\title{
Enhancing information distribution through open access publishing
}

SADJ September 2020, Vol. 75 No. 8 p410

NH Wood

Managing Editor of the SADJ

The South African Dental Journal is steadfastly moving deeper into the open access realm. This brings with it some challenges and concerns that the editorial team need to be aware of and manage accordingly. However, many positives are gained from this position that include improved article distribution and visibility, better knowledge dissemination, and improved manuscript management to name a few.

Academic journal subscriptions became increasingly expensive over a number of years as publishing companies saw that there was profit to be made from charging libraries, scholars and readers with fees to access scientific papers. The cost of this access keeps rising which raises the question: "why is this cost necessary?".

There are certainly costs to be covered by the journal and publishers in the process from the article submission to the publication thereof, and reasonable fees can be built in through different mechanisms and are justifiable. But is an exorbitantly high cost justified?

Many view this paywall as simply blocking access to scientific material and obstructing scientific progress and the dissemination of knowledge to anyone who needs it for the sake of making money. And those making the money are not the authors, neither the reviewers nor the journal itself. It is therefore not morally acceptable to hold scientific progression at ransom for profit.

Academics and prominent academic institutions globally are making efforts to break down this restrictive paywall. The knowledge revolution is also gaining popularity among scientific funders, many of whom now demand that the research they fund be published as open

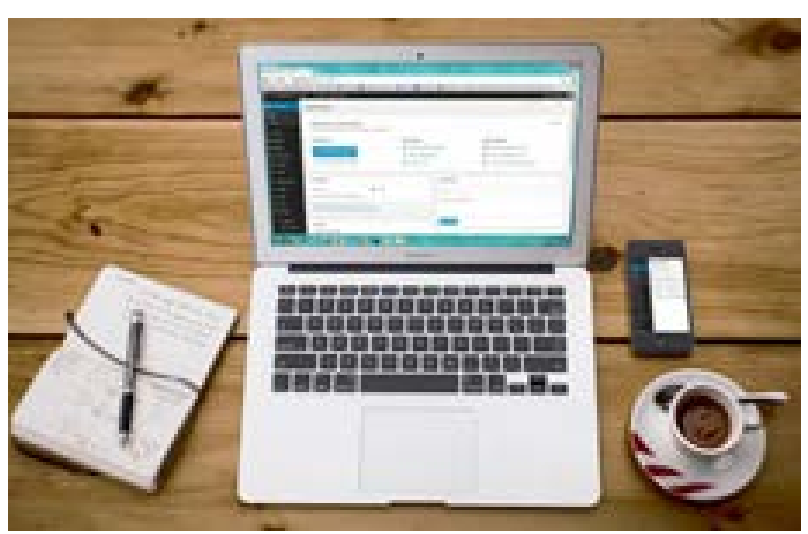

Neil H Wood: Managing editor. Email: neil.wood@smu.ac.za

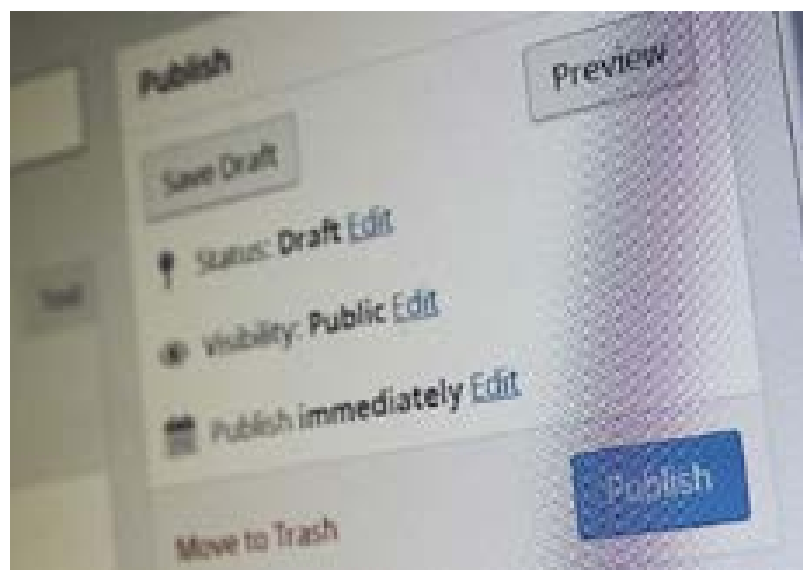

access. It is my view that we must strive to provide the latest scientific developments and information from the knowledge frontier to anyone who seeks it. As such, the SADJ will be hosted on the Khulisa platform which will soon be accessible at https://journals.assaf.org.za/ index.php/sadj.

There is some concern regarding the endurance of open access journals and papers on the web. ${ }^{1}$ There have been instances where journals and/or articles have disappeared off the web, but this was mainly as a result of non-attendance. At the SADJ every effort is made to ensure our material is backed up to protect the SADJ against such information loss with the South African Dental Association also acting as the preservation custodian for the journal. In this way the knowledge contained in the archives of the SADJ will be available to many generations after ours. We once again thank our contributors for the content in this September issue of the South African Dental Journal.

\section{References}

1. https://www.theregister.com/AMP/2020/09/10/open_ access_journal/. 